\title{
EDUCAÇÃO SUPERIOR PÚBLICA A DISTÂNCIA NA BAHIA: AVANÇOS E CONTRADIÇÕES
}

\author{
Emanuel do Rosário Santos Nonato* \\ Mary Valda Souza Sales**
}

\begin{abstract}
RESUMO
O estudo em tela tem por objetivo analisar o histórico de oferta pública de ensino superior a distância na Bahia para identificar seus avanços e contradições a partir do problema de pesquisa: como a oferta pública de ensino superior a distância na Bahia se conforma ante os avanços e contradições desse processo? A metodologia utilizada é a pesquisa documental. Em vista da proeminência da UNEB no quadro de oferta de vagas públicas na modalidade de Educação a Distância na Bahia, o estudo centraliza sua abordagem na experiência da UNEB. Abordando as bases legais para o desenvolvimento da EAD no Ensino Superior, a implementação do Sistema Universidade Aberta do Brasil no estado da Bahia, as experiências pré-UAB e a inserção de EAD nos cursos presenciais de graduação, este estudo identifica os avanços e as contradições do processo de assimilação da Educação a Distância pelas universidades públicas baianas, a configuração do quadro de vagas de Educação Superior Pública na Bahia resultante das políticas de oferta de cursos a distância e os impactos dessa oferta na estrutura organizacional da universidade.
\end{abstract}

Palavras-chave: Educação superior pública. Educação a Distância. Universidade Aberta do Brasil.

\section{ABSTRACT \\ PUBLIC HIGHER DISTANCE EDUCATION IN BAHIA: ADVANCES AND CONTRADICTIONS}

This study seeks to analyze the history of distance higher education offered by the public educational system of the state of Bahia in order to identify its advances and contradictions in relation to the following question under investigation: how does the state's providing of distance higher education in Bahia adjust itself in relation to the progress and contradictions inherent in this process? The methodology adopted employs documental research. Considering the prominence of the State University of Bahia (UNEB) in relation to the number of online higher education courses offered in Bahia, this research focuses on the UNEB experience. It addresses the legal basis for the development of distance education at the higher education level, the implementation

\footnotetext{
* Doutor em Difusão do Conhecimento pela Universidade Federal da Bahia (UFBA). Professor Adjunto da Universidade do Estado da Bahia (UNEB). Endereço para correspondência: Rua Maria Conceição Rego, 191 - Casa 01, Condomínio Bilbao, Buraquinho, Lauro de Freitas - Bahia, CEP: 42700-000. E-mail: enonato@uneb.br

** Doutora em Educação pela Universidade Federal da Bahia (UFBA). Professora Adjunta da Universidade do Estado da Bahia (UNEB). Endereço para correspondência: Alameda Praia de Atalaia, 410 - Residencial Mar Onda Branca, casa 01 - Stella Maria, Salvador - Bahia. CEP 41600-020. E-mail: marysales@uneb.br
} 
of Brazil's Open University (UAB) system in Bahia - and experiences that existed prior to its adoption - and the integration of distance education in traditional university classrooms. This article identifies the advances and contradictions that accompanied the process of assimilation of distance education by Bahia's state universities. It also looks at the ways in which the framework of public higher education in Bahia was modified as a result of the introduction of distance education and the impact that its implementation has had upon on the organizational structure of the university.

Key words: Public Higher Education. Distance Education. Brazil Open University.

\section{RESUMEN}

\section{EDUCACIÓN SUPERIOR PÚBLICA A DISTANCIA EN BAHIA: AVANCES Y CONTRADICCIONES}

El estudio propuesto tiene por objetivo analizar el histórico de oferta pública de la educación superior a distancia en Bahia para identificar sus avances y contradicciones a partir del problema de investigación: ¿Cómo la oferta pública de educación superior a distancia en Bahia se conforma ante los avances y contradicciones de este proceso? La metodología utilizada es la investigación documental. En vista de la prominencia de la UNEB en cuanto a la oferta de vacantes públicas en la modalidad de Educación a Distancia en Bahia, el estudio se centra en los abordajes de la experiencia de la UNEB. Abordando las bases legales para el desarrollo de la EAD en la educación superior y la implementación del sistema de Universidad Abierta de Brasil. Las experiencias pre-UAB y la inserción de la EAD en los cursos presenciales de graduación, este estudio identifica los avances y las contradicciones de procesos de asimilación de Educación a Distancia por las universidades publicas bahianas, la configuración en cuanto a las vacantes de Educación Superior en Bahia resultante de las políticas de oferta en cursos a distancia y los impactos de esta oferta en la estructura organizacional de la universidad.

Palabras Claves: Educación Superior Publica, Educación a Distancia, Universidad Abierta de Brasil.

\section{1 introdução}

A Bahia convive há mais de uma década com políticas públicas de oferta de ensino superior público na modalidade de Educação a Distância (EAD). No curso desse processo, as estruturas de fomento variaram em objetivo e formato, mas convergiram na natureza de programas especiais com o objetivo de responder a uma demanda pontual do Estado por formação de professores da Educação Básica na quase totalidade dos casos. Já aqui, duas características fundamentais dessa experiência emergem como constantes: a natureza de programa especial e o foco na formação de professores.
Esse cenário referente ao fenômeno da EAD no ensino superior na Bahia leva o pesquisador ao enfrentamento de uma realidade contraditória: ao tempo em que o aumento consistente do número de vagas de ensino superior público a distância e sua forte interiorização é um avanço incontestável, a condição de programa especial que marca os cursos ofertados na modalidade EAD mantém sobre as vagas criadas nesses cursos a marca da transitoriedade, impedindo o aprofundamento das estruturas acadêmicas e a solidificação da EAD como uma modalidade plenamente integrada ao fazer pedagógico das universidades baianas.

A história da oferta de educação superior pública a distância na Bahia começa com uma política 
estadual de financiamento para formação inicial de professores da Rede Estadual de Ensino, continua com o Pró-Licenciatura e chega ao modelo atual do Sistema Universidade Aberta do Brasil. Nesses três momentos, o foco na formação de professores e a condição de programas especiais caracterizaram a oferta de EAD pública na Bahia e realçaram a contradição: essas ações aumentaram o número de vagas, mas não foram capazes de levar a uma estabilidade institucional da modalidade EAD no cenário do ensino superior público, bem como não atingiram a totalidade do Ensino Superior, restringindo-se fundamentalmente a licenciaturas.

Não obstante não se possa e não se queira negar os evidentes avanços que essas políticas trouxeram para a EAD nas Instituições Públicas de Ensino Superior (IPES) do estado da Bahia, na medida em que: instigaram a discussão teórica; contribuíram decisivamente para a construção de estruturas de gestão de EAD, embora ainda frágeis; possibilitaram o desenvolvimento de massa crítica no âmbito das IPES. Contudo, as graves contradições que emergem desse processo, na medida em que, passados mais de quinze anos de seu início, as IPES baianas não conseguiram consolidar a EAD como uma modalidade plenamente integrada à vida acadêmica dessas instituições, levam à necessidade de uma análise do problema de pesquisa que mobiliza este estudo, qual seja: como a oferta pública de ensino superior a distância na Bahia se conforma ante os avanços e contradições desse processo?

Para tanto, utilizando a metodologia de pesquisa documental, este estudo analisa o histórico do processo de oferta de ensino superior público a distância na Bahia, considerando suas contradições e seus avanços, para determinar o estágio de consolidação da EAD nas IPES baianas e indicar as contradições que precisam ser superadas a fim de acelerar e consolidar esse processo. Assim, este estudo quer também apontar caminhos no sentido de propor uma reflexão em torno da consolidação da EAD no ensino superior público da Bahia a partir da experiência concreta das IPES baianas.

Nesse sentido, objetivando analisar o histórico de oferta pública de ensino superior a distância na Bahia para, a partir da identificação de seus avanços e contradições, contribuir com o processo de consolidação da EAD nas IPES baianas, foram co- limados como objetivos específicos: compreender o processo histórico de desenvolvimento da EAD nas IPES baianas; identificar as estruturas institucionais de EAD nas universidades públicas da Bahia; analisar os impactos das políticas públicas de fomento à oferta de ensino superior público a distância na Bahia.

\section{Metodologia (Pesquisa Documental)}

A pesquisa documental é um método de pesquisa "pouco explorada não só na área da educação como em outras áreas das ciências sociais", como afirmam Ludke e André (1986, p. 38). Embora a utilização de documentos no desenvolvimento de pesquisas seja permanente, nem sempre isto é valorizado per se, pois a riqueza de acesso a informações e conhecimentos que podem ser observados e extraídos mediante essa metodologia é muito significativa. Nas Ciências Humanas e Sociais, a pesquisa documental torna-se um aparato importantíssimo para a compreensão e contextualização da ambiência na qual são desenvolvidas as pesquisas. Nesse sentido, podemos afirmar que o documento

[...] se constitui numa fonte extremamente preciosa para todo pesquisador nas ciências sociais. Ele é, evidentemente, insubstituível em qualquer reconstituição referente a um passado relativamente distante, pois não é raro que ele represente a quase totalidade dos vestígios de atividade humana em determinadas épocas. Além disso, muito frequentemente, ele permanece como único testemunho de atividades particulares ocorridas num passado recente. (CELLARD, 2008, p. 295).

Nessa direção, os documentos são também uma fonte de dados e informações sobre ações e atividades atuais nos quais podemos perceber $o$ desenvolvimento das sociedades com retratos sistemáticos de questões bem específicas a partir das estatísticas feitas, favorecendo a visualização da dimensão de cada atividade, ação, lei, projeto, prática e da maturação e evolução dos grupos sociais, dos indivíduos, da sociedade de maneira geral.

Segundo Sá-Silva, Almeida e Guindani (2009, p. 3), a pesquisa documental é

[...] um método de coleta de dados que elimina, ao menos em parte, a eventualidade de qualquer influ- 
ência - presença ou intervenção do pesquisador - do conjunto das interações, acontecimentos ou comportamentos pesquisados, anulando a possibilidade de reação do sujeito à operação de medida.

Dessa forma, ela contribui para que se possa fazer uma descrição densa do fenômeno pesquisado com a comprovação direta e explícita de dados já registrados, confirmados.

Considerando tais argumentos, esta pesquisa está fundada sobre a análise dos seguintes documentos de referência:

a) Legislação Nacional de EAD - que subsidia as discussões sobre a legalização da modalidade no nosso país e as condições de oferta nas IPES;

b) Projeto "guarda-chuva" do Consórcio Bahia - que explicita características e ações do processo de implementação da EAD no nosso estado, bem como as ações próprias de cada IPES no processo de consolidação das ofertas, além da importância do projeto UAB nesse contexto;

c) Resoluções da UNEB sobre EAD - que demarcam o processo evolutivo da implantação da EAD na UNEB;

d) Relatórios dos SIS/UAB/UNEB - nos quais constam os dados gerais de oferta por curso, nível, quantitativo de participantes, condições de oferta, polos etc.;

e) Censo Nacional de EAD de 2013 - que dá um retrato do desenvolvimento da EAD no Brasil, na região Nordeste e na Bahia.

Procedeu-se a análise dos documentos a partir dos seguintes critérios:

a) Para os documentos legais (resoluções, leis), extraíram-se os tópicos que correspondiam às necessidades do problema ora investigado;

b) Para o documento institucional (projeto guarda-chuva), destacaram-se as indicações de atendimento à legislação nacional e às necessidades da UNEB em relação à implantação da EAD;

c) Para os relatórios (Censo Nacional e SisUAB), foram identificados os dados necessários para fortalecer os argumentos e constituir um mapa de trabalho sobre o quadro da EAD na Bahia.
Com os referidos critérios, construiu-se um mapa de referência com os dados quantitativos da EAD na UNEB, a fim de estabelecer uma relação direta com o histórico construído com base nos documentos analisados. Tais documentos possibilitaram a consecução dos objetivos propostos, de maneira a responder o problema de pesquisa ora apresentado e expor um retrato da EAD na UNEB.

\section{EAD: bases legais e modelos}

No cenário nacional, a Educação a Distância (EAD) "tem marcado sua presença, fazendo uso de diferentes tecnologias, desde o material impresso, passando pelo rádio, televisão, até chegar aos computadores em rede" (SALES, 2006, p. 44). O avanço e o aperfeiçoamento das Tecnologias da Informação e da Comunicação (TIC) impulsionaram essa forma de se fazer e pensar a educação, colocando-a em evidência a partir da última década do século passado. Isto inspirou pesquisadores e instituições a mergulharem nesse contexto e buscar aproximações com as "diferentes" formas de se fazer educação e de uso das tecnologias em geral. É nesse movimento que a EAD invade o contexto universitário, emergindo nas propostas das políticas públicas do Brasil como uma das formas mais eficazes de garantia do acesso à educação superior por conta da dimensão geográfica do nosso país e da gama de possibilidades tecnológicas que podem e são utilizadas para garantir esse acesso. ${ }^{1}$

Esse processo fez da EAD "a educação que chega às pessoas no lugar onde elas se encontram e com a flexibilidade de utilização do tempo que se gesta de acordo com a disponibilidade de cada estudante" (SALES, 2006, p. 29), além de possibilitar o contato com tecnologias diversas. Essa realidade já encontra eco em experiências/modelos de EAD dessa nova geração iniciada nos anos de 1970 que foram exitosas, notadamente a Open University na Inglaterra e êxitos similares também obtidos

\footnotetext{
1 Vale destacar que aqui não está em discussão a política de acesso ao ensino superior e nem uma análise crítica dessa perspectiva de estímulo e uso da EAD. Salientamos que nossa posição política é da garantia da qualidade da educação, independentemente da modalidade, e que a EAD não pode ser vista como essa "tábua de salvação", ou pelo menos posta, uma vez que sabemos que o processo de implementação de suas práticas não são tão simples e dependem da formação de cultura, de pessoas e de mudança de atitudes pedagógicas.
} 
pela Espanha e pela Venezuela, conforme salienta Nunes (2009). ${ }^{2}$

No Brasil, a educação a distância teve início em 1923, via rádio, perdurando entre avanços e percalços até 1969 , quando a censura matou a rádio educativa brasileira. Entre as décadas de 1960 e 1970, a televisão passou a ser utilizada fortemente para fins educacionais, recebendo vários incentivos governamentais e privados. Nesse período, a educação a distância ganhou força com a criação do Programa Nacional de Teleducação (Prontel). Em 1994, o Sistema Nacional de Radiodifusão Educativa foi totalmente reformulado e a Fundação Roquete Pinto passou a coordenar suas ações.

Como os canais abertos de televisão utilizavam horários incompatíveis para a transmissão dos programas educativos, mesmo com a iniciativa positiva da Fundação Roberto Marinho com alguns programas educacionais específicos como o Telecurso, o caminho da educação a distância através dos canais abertos não logrou sucesso. Outras iniciativas exitosas foram gestadas com o surgimento do sistema de TV fechada, tais como as TV Universitárias, o Canal Futura, a TV Cultura. Dentre elas, destaca-se a TV Escola, mantida pelo governo federal, ${ }^{3}$ e que gera programas que alimentam a EAD nacional até os dias atuais (SALES, 2006).

Essa breve retrospectiva demonstra a posição que a educação a distância teve com programas, projetos e ações específicas de formação continuada para diversos segmentos educacionais ou não. Todavia, no Brasil, ela demorou a adentrar o contexto universitário, mesmo sendo entendida como "possibilidade" importante para o desenvolvimento das ações de formação e de certificação na educação básica, na educação corporativa e na educação informal. Faltava à EAD a legitimidade que a Lei de Diretrizes e Bases da Educação ${ }^{\circ}$ 9394/96 (LDB) 1he concedeu, tornando-a uma modalidade plenamente integrada ao arcabouço

2 Para conhecer um pouco mais sobre a história da EAD no mundo, pode-se conferir o livro Educação a Distância: o Estado da Arte, organizado pelos professores Freddric M. Litto e Marcos Formiga (2009).

3 Mais informações detalhadas e específicas sobre a evolução da EAD no Brasil podem ser encontradas no Censo EAD.BR de 2013 (ASSOCIAÇÃO BRASILEIRA DE EDUCAÇÃO A DISTÂNCIA, 2014) e no livro de Litto e Formiga (2009), além dos sites do Ministério da Educação e da Universidade Aberta do Brasil. jurídico da educação nacional mediante a conformação que lhe dão os artigos 80 e 87 da referida lei, permitindo sua institucionalização no âmbito da Educação Superior (BRASIL, 1996).

Com as possibilidades geradas pelo uso das TIC para produção e difusão do conhecimento como retroalimentadora dos processos geradores das inovações, a EAD adentra a universidade ${ }^{4}$ fortemente influenciada pelo impacto e avanços causados pela revolução tecnológica do final do século XX, mais especificamente pelas TIC nos modos, processos e condições de aprendizagem e de formação. No entanto, ela ainda não se adaptou totalmente a essa realidade com o uso potencial dessas tecnologias nos processos educativos no contexto universitário. Nessa linha, é muito elucidativo esse processo de inserção da EAD na Educação Superior à luz do que Castells (2003, p. 69) pontua sobre o processo tecnológico e econômico que marcou a emergência do Capitalismo Informacional:

[...] o que caracteriza a atual [à época] revolução tecnológica não é a centralidade de conhecimentos e informação, mas a aplicação desses conhecimentos e dessa informação para a geração de conhecimentos e de dispositivos de processamento/comunicação da informação, em um ciclo de realimentação cumulativo entre a inovação e seu uso.

Assim, a EAD adentra o ensino superior com a perspectiva de também auxiliar no processo de maximização da aquisição e aplicação de conhecimentos, como uma modalidade adicional de formação profissional, intelectual e social dos sujeitos e da sociedade de maneira geral. A EAD entra também como possibilidade de modernização e maximização das ações de gestão administrativa, pedagógica e financeira, uma vez que a educação superior tem hoje a necessidade de atender a uma demanda crescente de acesso ao conhecimento e à formação, no sentido de dar conta das exigências da sociedade contemporânea na modernização estrutural dos processos pedagógicos e de gestão. Nessa perspectiva, também as TIC trazem para mais próximo do contexto universitário as comunidades locais através da oferta de ações formativas e reflexivas sobre o uso das TIC nos diversos setores

4 O termo universidade será utilizado de forma genérica para referenciar-se aos diferentes tipos de instituições de educação superior. 
da sociedade, utilizando-as como "meios" de oferta dessa formação e de outras possibilidades de acesso ao ensino superior.

As experiências citadas e o aparato jurídico proporcionado pelos artigos 80 e 87 da LDB vigente levaram à criação de uma série de normas infralegais para normatizar a $E A D$, visto que a $L D B$ sozinha não se mostrava suficiente para atender às necessidades apresentadas pelas diversas instituições no que diz respeito a esclarecimentos sobre forma e condições de oferta, modelos e metodologias, avaliação e credenciamento das instituições para EAD.

Nesse sentido, ante as propostas e ações que se seguiram à LDB 9394/96, surgidas principalmente no seio das universidades brasileiras que passaram a ofertar cursos de graduação a distância, tornou-se imprescindível a necessidade de regulação das questões próprias da $\mathrm{EAD}$ que não encontravam amparo na norma geral da educação, não obstante a oferta de EAD no ensino superior brasileiro se restringisse quase que sempre a cursos de formação de professores na busca do atendimento ao chamado contido na referida lei para a universalização da licenciatura como formação inicial para o exercício do magistério.

Nesse sentido, em 1998, o Decreto 2.494/98 (BRASIL, 1998a) regulamentou os artigos $80 \mathrm{e}$ 87 da LDB. Posteriormente, esse decreto teve sua redação alterada nos artigos 11 e 12 pelo Decreto $\mathrm{n}^{\mathrm{o}}$ 2.561/98 (BRASIL, 1998b), definindo que apenas o MEC poderia credenciar as instituições de ensino superior existentes no país para oferta de cursos de graduação e a formação tecnológica a distância.

Com a demanda crescendo, o MEC precisou normatizar alguns procedimentos específicos da EAD. Isto posto, com a Portaria Ministerial $\mathrm{n}^{\circ}$ 301/98 (BRASIL, 1998c) adveio a normatização dos procedimentos de credenciamento das instituições para a oferta de cursos de graduação e educação profissional tecnológica a distância, os quais iniciaram uma onda de crescimento nesse mesmo ano por todo o Brasil.

Com a oficialização da oferta de cursos a distância no Brasil, o Conselho Nacional de Educação (CNE), através da Resolução $n^{\circ} 1 / 2001$, estabeleceu as normas para o funcionamento de cursos de pós-graduação lato e stricto sensu na modalidade a distância, fixando limites e estabelecendo exigências para o reconhecimento dos cursos a distância ofertados por instituições estrangeiras, impedindo a instalação de um processo de impregnação da educação estrangeira no ensino superior nacional (BRASIL, 2001a).

Em atenção às solicitações das Instituições de Ensino Superior (IES), o MEC permitiu que as universidades, faculdades e centros universitários e tecnológicos pudessem oferecer $20 \%$ do tempo previsto para integralização da carga horária do currículo de cursos presenciais na modalidade a distância, oportunizando a inserção da EAD nos cursos presenciais, através da Portaria Ministerial $\mathrm{n}^{\mathrm{o}} 2.253 / 01$ (BRASIL, 2001b). Isto possibilitou a apropriação tecnológica e metodológica da modalidade, bem como a adaptação das IES a uma nova forma de ofertar educação.

A crescente oferta demandou também a constituição de uma comissão para assessorar e analisar os processos legais e de desenvolvimento da EAD no país, o que foi consolidado pela Portaria Ministerial $n^{0} 335 / 02$, que criou a Comissão Assessora para a Educação Superior a Distância (BRASIL, 2002).

No início dos anos 2000, a EAD representava novas e diferentes perspectivas para diversos segmentos educacionais e coorporativos com a oferta de cursos diversos na modalidade a distância. Esse movimento crescente acelerou o processo de regulamentação do art. 80 da LDB 9.394/96 com o Decreto $\mathrm{n}^{\circ} 5.622 / 2005$, que estabelece as diretrizes e bases para a educação a distância no Brasil (BRASIL, 2005). Em 2006, passou a vigorar também o Decreto 5.773/2006, que dispõe sobre o exercício das funções de regulação, supervisão e avaliação de instituições de educação superior e cursos superiores de graduação e sequenciais no sistema federal de ensino, autorizando o funcionamento de cursos a distância em todas as IFES brasileiras (BRASIL, 2006a).

Com o intuito de regulamentar a EAD de maneira geral, em 12 de dezembro de 2007 passa a vigorar o Decreto 6.303, que altera os dispositivos do Decreto ${ }^{\circ} 5.622 / 2005$ e do $n^{\circ} 5.773 / 2006$, deixando claras em uma só legislação as diretrizes e bases da EAD nacional (BRASIL, 2007a). 
Em 2007, três portarias normativas passaram a vigorar a fim de normatizar o processo de avaliação da EAD: a $n^{\circ} 1$, que regula as avaliações de cursos; a $n^{\circ} 2$, que versa sobre a regulação e avaliação da EAD superior; e a $n^{0} 10$, que estabelece os critérios para dispensa da avaliação in loco das instituições. Além dessas três portarias normativas, nesse mesmo ano ainda foi publicada a Portaria $\mathrm{n}^{\mathbf{}}$ 40, que institui o e-MEC (BRASIL, 2007b, 2007c, 2007d, 2007e).

Explicitar temporalmente a legislação da EAD no Brasil contribui para lançar luz sobre seu desenvolvimento nas instituições de ensino superior e também para apresentar os dois modelos vigentes da EAD no país, na medida em que seguem a orientação dos Referenciais de Qualidade para EAD. Isto também demonstra como o aparato jurídico que sustenta a EAD foi se construindo paulatinamente, no ritmo das demandas, na tentativa de regular um processo dinâmico já em curso.

Em relação aos modelos de curso, hoje, no Brasil, existem duas formas de classificação: um modelo definido a partir do tipo de tecnologia utilizada para oferta e outro modelo definido de acordo com a proposta pedagógica de aprendizagem adotada.

Os modelos definidos a partir do tipo de tecnologia utilizada, consoante o que expõem Peters (2003), Aretio (1987), Belloni (2006) e Sales (2006), podem ser:

a) Semipresencial - modelo de curso que faz uso de tecnologias digitais e telemáticas, assim como das tecnologias tradicionais, tais como módulos, fascículos, livros, dentre outras, e de encontros presenciais para ações pedagógicas diversas;

b) Virtual - são os cursos mais conhecidos como e-learning, totalmente virtuais, que normalmente utilizam as tecnologias digitais com acesso à rede mundial de computadores (Internet) para serem desenvolvidos em ambientes virtuais totalmente integrados a diversos recursos de comunicação e informação.

Podemos também afirmar que, após a análise de cursos de graduação e formação continuada na modalidade EAD ofertados por instituições públicas e privadas, a classificação destes de acordo com a proposta pedagógica de aprendizagem, o desenho pedagógico definido para o curso se encaixam nos modelos:

a) Autoinstrucional - aqueles que permitem que o estudante, guiado pelo material didático, possa desenvolver o curso sem mediação do processo, apenas com o auxílio do material didático disponível;

b) Instrucional/Mediado - aqueles que fornecem todo o material de estudo e também a mediação de professores tutores ou professores no desenvolvimento do curso, das atividades. São os cursos que possuem um desenho pedagógico com interação pedagógica entre professores e estudantes;

c) Livre/Aberto - são os cursos que não possuem desenho pedagógico definido inicialmente, pois este é construído no desenvolvimento dos mesmos. Neste modelo pedagógico de curso tem-se apenas definida a proposta de formação e todos os participantes são autores, coprodutores e cursistas do mesmo curso. Todos ensinam e todos aprendem.

Vale salientar que estudiosos como Filatro (2004, 2008) Peters (2003, 2004), Aretio (1987), Keegan (1993) e Holmberg (1989) têm, ao longo dos últimos 30 anos, pesquisado e delineado modelos de curso a distância a partir de perspectivas diversas. Todavia, todos eles apresentam um ponto em comum que é a identificação do tipo de tecnologia de comunicação e acesso ao conhecimento e informação que é utilizada. Ademais, esses autores reconhecem que para todo e qualquer modelo ou tipo de curso existem sujeitos que ensinam e aprendem, existe a necessidade de professor e de estudante. Tal assertiva traça uma linha na areia que separa a discussão sobre EAD dos temores de natureza trabalhista que assombravam muitos.

Os modelos de curso, sejam eles quais forem, são delineados considerando sempre a confluência entre todos os aspectos envolvidos, isto é, considerando a tecnologia escolhida para oferta do curso, a proposta pedagógica de aprendizagem e o desenho 
pedagógico proposto, uma vez que os cursos podem ser constituídos de formas variadas, definindo sua organização e funcionamento pedagógico a partir do modelo de gestão pedagógica utilizado e da definição dos papéis dos participantes/integrantes de um curso EAD. Esses papéis são normalmente assim identificados:

a) Professor Autor - é o especialista no campo do conhecimento que elabora o material didático do curso;

b) Professor Formador - é o organizador pedagógico da sala de aula virtual e aquele que elabora e implementa as ações e atividades constituintes da prática pedagógica (atividades e avaliação);

c) Professor Tutor - é aquele responsável pela mediação pedagógica e acompanhamento dos estudantes. Em alguns modelos de curso, é o profissional que assume as funções inerentes à docência no Ambiente Virtual de Aprendizagem (AVA);

d) Monitor - normalmente é o profissional responsável pelo monitoramento e acompanhamento das atividades do curso;

e) Cursista - é o estudante propriamente dito.

A partir do modelo de curso definido, esses participantes têm seus papéis implementados na proposta pedagógica do curso conforme os objetivos de construção e difusão do conhecimento, de comunicação, de interação e de aprendizagem definidos, podendo haver confluência entre as funções e até a não existência de algumas. Desse modo, pode-se ter um modelo totalmente virtual, como por exemplo um curso com um desenho pedagógico autoinstrucional ou mediado, dependendo única e exclusivamente das tecnologias utilizadas e do objetivo de desenvolvimento e formação do mesmo.

No Brasil, com a emergência da EAD como modalidade e possibilidade de desenvolvimento de cursos de formação no âmbito da educação formal, principalmente de formação de professores, o modelo mais adotado no ensino superior é o semipresencial, tendo em vista as exigências legais para oferta dos cursos, a dimensão geográfica do Brasil e a estrutura das instituições de ensino superior, principalmente as públicas, que, na sua grande maioria, efetivam as ofertas dentro do Sistema UAB.

\section{Ensino Público Superior a Distância e a Universidade Aberta do Brasil}

A reflexão a respeito do ensino superior público a distância na Bahia e no Brasil leva-nos inicialmente a refletir sobre a relação entre ensino superior e tecnologia, uma vez que essa relação é fundamental para a implementação da EAD. No entanto, essa reflexão remete-nos imediatamente ao problema da infraestrutura física e tecnológica e do financiamento, pontos que apresentam muitas dificuldades no que se refere às instituições públicas, devido ao sucateamento, à falta de recursos necessários a sua manutenção e modernização.

A infraestrutura de Tecnologia da Informação (TI) no Brasil é especialmente sensível na medida em que limita as ações das instituições públicas e privadas e restringe a possibilidade de imersão da EAD nos ambientes de maiores assimetrias sociais e econômicas. Esta questão, por complexa, demanda uma análise mais detida, que não cabe no escopo deste estudo. Contudo, há de se salientar que as graves deficiências em infraestrutura de TI no Brasil, notadamente nas regiões e localidades mais afastadas dos grandes centros urbanos, bem como as limitações de investimento em infraestrutura tecnológica por parte das universidades públicas, leva ao paradoxo de a EAD em seu formato mais dinâmico e atual ficar restrita aos grandes centros urbanos que possuem condições mínimas de infraestrutura de TI para a viabilização dos cursos online, em detrimento das regiões e localidades mais distantes, mais afastadas das grandes estruturas públicas de oferta de educação superior presencial, das comunidades mais carentes de educação superior pública e gratuita.

Isso posto, um olhar sobre a realidade hodierna referente aos credenciamentos e ofertas da EAD permite uma análise do contexto da Bahia em relação aos aspectos da estrutura, financiamento e de recursos humanos, conforme a Tabela 1. 
Tabela 1 - Número de Instituições de Educação Superior de graduação presencial e a distância por categoria administrativa - Brasil - 2002-2012

\begin{tabular}{|c|c|c|c|c|c|c|c|c|c|c|c|c|}
\hline \multirow{4}{*}{ Ano } & \multicolumn{6}{|c|}{ Presencial } & \multicolumn{6}{|c|}{ Distância } \\
\hline & \multirow{3}{*}{$\begin{array}{l}\text { Total } \\
\text { Geral }\end{array}$} & \multicolumn{5}{|c|}{ Categoria Administrativa } & \multirow{3}{*}{$\begin{array}{l}\text { Total } \\
\text { Geral }\end{array}$} & \multicolumn{5}{|c|}{ Categoria Administrativa } \\
\hline & & \multirow{2}{*}{ Total } & \multicolumn{3}{|c|}{ Pública } & \multirow{2}{*}{ Privada } & & \multirow{2}{*}{ Total } & \multicolumn{3}{|c|}{ Pública } & \multirow{2}{*}{ Privada } \\
\hline & & & Federal & Estadual & Municipal & & & & Federal & Estadual & Municipal & \\
\hline 2002 & 1.636 & 195 & 73 & 65 & 57 & 1.441 & 25 & 16 & 9 & 7 & - & 9 \\
\hline 2003 & 1.858 & 207 & 83 & 65 & 59 & 1.651 & 37 & 21 & 13 & 8 & - & 13 \\
\hline 2004 & 2.010 & 224 & 87 & 75 & 62 & 1.786 & 45 & 24 & 13 & 10 & 1 & 21 \\
\hline 2005 & 2.162 & 231 & 97 & 75 & 59 & 1.931 & 61 & 24 & 14 & 9 & 1 & 37 \\
\hline 2006 & 2.266 & 248 & 105 & 83 & 60 & 2.018 & 77 & 33 & 22 & 10 & 1 & 44 \\
\hline 2007 & 2.276 & 249 & 106 & 82 & 61 & 2.027 & 97 & 48 & 34 & 13 & 1 & 49 \\
\hline 2008 & 2.248 & 236 & 93 & 82 & 61 & 2.012 & 115 & 59 & 42 & 16 & 1 & 56 \\
\hline 2009 & 2.310 & 245 & 94 & 84 & 67 & 2.065 & 129 & 69 & 48 & 19 & 2 & 60 \\
\hline 2010 & 2.373 & 278 & 99 & 108 & 71 & 2.095 & 135 & 67 & 48 & 18 & 1 & 68 \\
\hline 2011 & 2.361 & 284 & 103 & 110 & 71 & 2.077 & 142 & 73 & 53 & 18 & 2 & 69 \\
\hline 2012 & 2.412 & 304 & 103 & 116 & 85 & 2.108 & 150 & 80 & 58 & 18 & 4 & 70 \\
\hline
\end{tabular}

Fonte: Instituto Nacional de Estudos e Pesquisa em Educação Anísio Teixeira (2012).

Segundo o Censo EAD 2013-2014, “há em nosso país 2.648 IES, sendo 107 federais, 119 estaduais, 55 municipais e 2.367 particulares" (INSTITUTO NACIONAL DE ESTUDOS E PESQUISA EM EDUCAÇÃO ANÍSIO TEIXEIRA, 2012). Esse é um dado que apresenta um retrato oficial, embora se saiba que existem algumas instituições que estão com suas atividades a distância suspensas por motivos diversos. Alves (2005) afirma que, desse total, 196 são universidades, 186 são centros universitários e 2.266 são faculdades, fazendo que nos localizemos no universo das 196 universidades, tendo em vista que estamos refletindo sobre o ensino público superior a distância.

De acordo com os dados do Ministério da Educação (INSTITUTO NACIONAL DE ESTUDOS E PESQUISA EM EDUCAÇÃO ANÍSIO TEIXEIRA, 2012), dessas 196 universidades, 135 são credenciadas para oferta de EAD, perfazendo um total de $68,88 \%$. Considerando que as IPES sofrem quase todas a mesma situação de dificuldades financeiras, deficiências em infraestrutura e carência de pessoal técnico e docente desde os anos 1990, e que ações isoladas para oferta de EAD no século XXI demandam, principalmente, recursos humanos qualificados para a implementação das ações, a estratégia utilizada pelas instituições de ensino superior para a implementação de EAD foi a adoção de consórcios para juntar esforços e minimizar essas deficiências.

Nesse contexto, destacam-se algumas experiências: a experiência pioneira da Universidade Virtual do Centro-Oeste (Univir-CO), que, em 1998, reuniu UnB, UFMT, UFG, UFMS, Unemat, UEMS e Uniana como instituições consorciadas para oferta de cursos a distância; a Universidade Virtual Pública do Brasil (UniRede), em 1999, que reuniu 81 IPES e 07 consórcios regionais; o CEDERJ, que reuniu em 2000 todas as IES públicas federais e estaduais do Rio de Janeiro no sentido de consolidar a oferta da EAD. Outras ações regionais foram desenvolvidas e movimentaram o poder público federal a fim de também fomentar o desenvolvimento da EAD nas IPES do Brasil. Essas experiências, ainda ativas, contribuíram fortemente para criação da Universidade Aberta do Brasil (UAB).

O Sistema Universidade Aberta do Brasil (UAB) foi criado pelo Decreto $n^{\circ} 5.800 / 2006$ (BRASIL, 2006b). Foi uma ação implementada pelo MEC, com a parceria da Andifes, objetivando atender inicialmente a formação em nível superior de funcionários públicos, notadamente os professores da Educação Básica através das licenciaturas e os agentes da administração pública através do Programa Nacional de Formação em Administração 
Pública (PNAP), que contém uma Graduação em Administração e três pós-graduações lato sensu em Gestão Pública, Gestão Pública Municipal e Gestão em Saúde. Com o objetivo de atender a formação de qualquer cidadão, a UAB assumiu um enorme papel na oferta de diversos cursos de licenciatura, formando um grande número de professores no território nacional, e de bacharelado em Administração, além de oferecer acesso ao ensino superior público no âmbito da pós-graduação lato sensu, vinculado a várias instituições públicas estaduais e federais em todo o país.

Após a implantação da UAB, o acumulado de vagas ofertadas em EAD no país cresceu consideravelmente, possibilitando o acesso ao ensino superior de um maior número de pessoas da população brasileira, nos mais diversos lugares, como se pode depreender do Gráfico 1.

Gráfico 1 - Percentual acumulado de vagas ofertadas na modalidade EAD distribuídos por tipo de curso no Brasil até março 2013

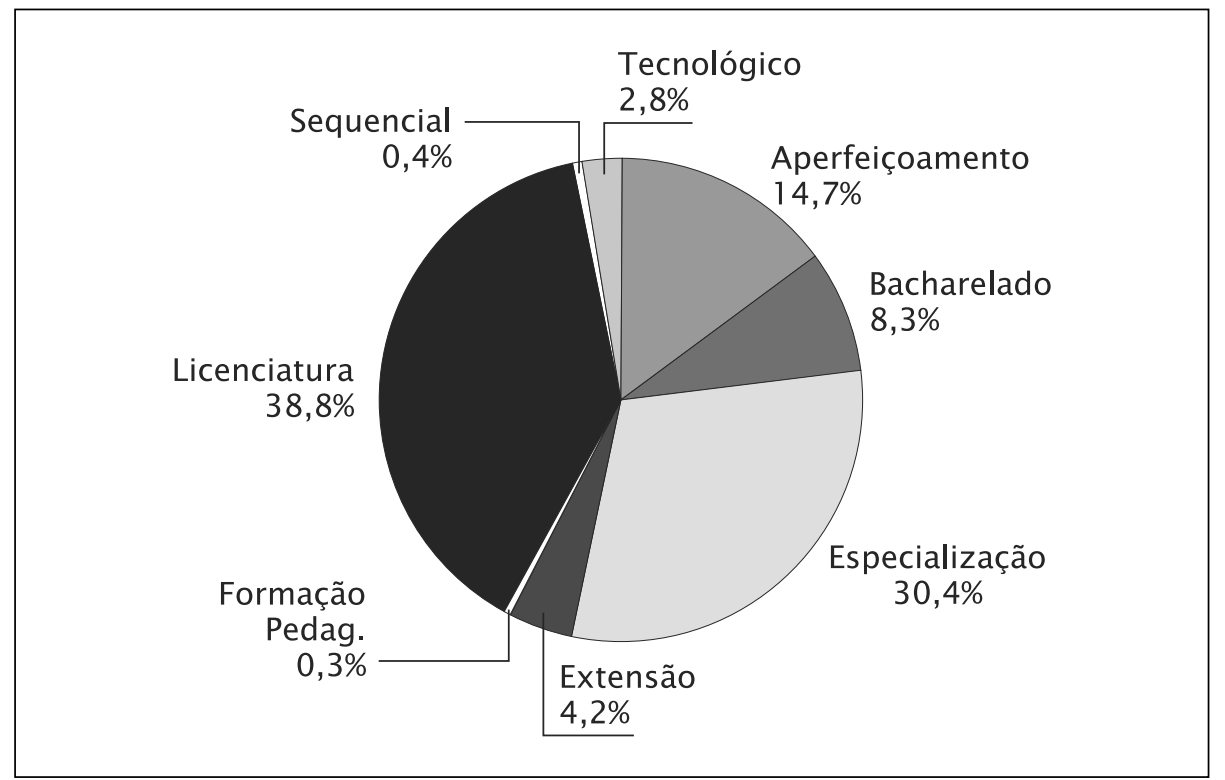

Fonte: Brasil (2014, p. 65).

Conforme demonstrado pelo Gráfico 1, a maior oferta é de cursos de licenciatura. Isto se dá pelo fato de que as políticas públicas de financiamento da EAD ainda buscam atender prioritariamente às necessidades de formação de professores que persistem no país, no que a UAB não se mostrou inovadora. Ao contrário, na esteira de outras ações de financiamento de EAD no Brasil, é significativo que o Sistema UAB financie quase que exclusivamente cursos de licenciatura, exceto o Programa Nacional de Formação em Administração Pública (PNAP). Tal contexto de financiamento tendencia fortemente o quadro de ofertas do ensino superior público a distância: premidas pelas graves restrições orçamentárias, as IPES assumem a execução dos cursos que são objeto de financiamento externo, dado o pouco ou nenhum espaço financeiro- -orçamentário para investir em EAD com recursos próprios e de modo autônomo, fazendo-o quase que exclusivamente com recursos de contratos, convênios ou descentralização de recursos. Em suma, a EAD pública que existe hoje é a EAD financiada pelo Sistema UAB.

Consoante esse quadro, os dados de oferta relativos especificadamente à $\mathrm{UAB}$ nesse mesmo período revelam o peso que as licenciaturas possuem no quadro geral de vagas do Sistema UAB. Nesse contexto, licenciatura e especializações vinculadas à docência possuem um quantitativo bem superior aos demais tipos de cursos ofertados devido aos projetos e políticas governamentais voltados à formação de professores da educação básica, objetivando alcançar os objetivos propostos pelo Plano Nacional de Educação. 
Tabela 2 - Vagas do Sistema UAB de 2005 a 2013

\begin{tabular}{lrrrrrrrrrr}
\hline Oferta de Vagas & $\mathbf{2 0 0 5}$ & $\mathbf{2 0 0 6}$ & $\mathbf{2 0 0 7}$ & $\mathbf{2 0 0 8}$ & $\mathbf{2 0 0 9}$ & $\mathbf{2 0 1 0}$ & $\mathbf{2 0 1 1}$ & $\mathbf{2 0 1 2}$ & $\mathbf{2 0 1 3}$ & Total \\
\hline Aperfeiçoamento & - & - & - & 2007 & 25666 & 31519 & 10425 & 18481 & 2750 & 90863 \\
Bacharelado & - & 30 & 2120 & 6200 & 7640 & 9300 & 6285 & 7886 & 11925 & 51416 \\
Especialização & - & - & 2788 & 12345 & 32041 & 47652 & 21585 & 32740 & 38413 & 187579 \\
Extensão & - & - & - & - & 1020 & 9635 & 7060 & 7363 & 1130 & 26208 \\
Formação Pedag. & - & - & - & - & 1126 & 30 & - & 854 & 125 & 2134 \\
Licenciatura & 120 & 445 & 11004 & 26977 & 49528 & 46494 & 39810 & 34019 & 31201 & 239628 \\
Sequencial & - & - & - & 835 & 550 & 794 & 50 & - & - & 2229 \\
Tecnológico & - & - & 2585 & 2440 & 2930 & 2765 & 1945 & 2428 & 2105 & 17198 \\
\hline Total & $\mathbf{1 2 0}$ & $\mathbf{4 7 5}$ & $\mathbf{1 8 4 9 7}$ & $\mathbf{5 0 8 0 4}$ & $\mathbf{1 2 0 5 0 1}$ & $\mathbf{1 4 8 1 8 9}$ & $\mathbf{8 7 1 6 0}$ & $\mathbf{1 0 3 7 7 1}$ & $\mathbf{8 7 6 4 9}$ & $\mathbf{6 1 7 2 5 6}$ \\
\hline
\end{tabular}

Fonte: Brasil (2014, p. 66).

Tabela 3 - Número de matriculados, ativos e concluintes UAB - 2007-2013

\begin{tabular}{|c|c|c|c|c|c|c|c|c|c|c|c|c|}
\hline \multirow[b]{2}{*}{ Modalidade } & \multicolumn{3}{|c|}{2007} & \multicolumn{3}{|c|}{2008} & \multicolumn{3}{|c|}{2009} & \multicolumn{3}{|c|}{2010} \\
\hline & Matrículas & Ativos & Concluintes & Matrículas & Ativos & Concluintes & Matriculas & Ativos & Concluintes & Matrículas & Ativos & Concluintes \\
\hline Licenciatura & 3.943 & 3.466 & 33 & 22.871 & 19.891 & 193 & 57.344 & 50.364 & 232 & 93.920 & 73.144 & 246 \\
\hline Formação Pedag. & - & - & - & - & - & - & 107 & 107 & - & 107 & 107 & - \\
\hline Bacharelado & 611 & 534 & - & 6.189 & 5.519 & - & 9.876 & 8.494 & - & 20.038 & 15.952 & - \\
\hline Tecnólogo & 1.677 & 1.366 & 216 & 4.023 & 3.209 & 299 & 6.694 & 4.986 & 359 & 8.316 & 4.640 & 552 \\
\hline Especialização & 2.362 & 1.278 & 585 & 9.988 & 3.700 & 3.288 & 23.793 & 9.869 & 7.490 & 59.540 & 38.706 & 9.901 \\
\hline Aperfeiçoamento & 15 & 15 & - & 229 & 79 & 238 & 20.636 & 2.969 & 10.898 & 32.871 & 9.398 & 14.599 \\
\hline Extensão & - & - & - & 65 & - & 40 & 351 & - & 259 & 1.195 & 394 & 510 \\
\hline Sequencial & - & - & - & 707 & 438 & 148 & 1.019 & 597 & 206 & 1.089 & 667 & 206 \\
\hline Mestrado Prof. & - & - & - & - & - & - & - & - & - & - & - & - \\
\hline Total & 8.609 & 6.659 & 834 & 44.292 & 32.836 & 4.206 & 119.820 & 77.386 & 19.444 & 217.076 & 143.008 & 26.014 \\
\hline
\end{tabular}

\begin{tabular}{|c|c|c|c|c|c|c|c|c|c|}
\hline \multirow[b]{2}{*}{ Modalidade } & \multicolumn{3}{|c|}{2011} & \multicolumn{3}{|c|}{2012} & \multicolumn{3}{|c|}{2013} \\
\hline & Matrículas & Ativos & Concluintes & Matriculas & Ativos & Concluintes & Matriculas & Ativos & Concluintes \\
\hline Licenciatura & 131.854 & 104.290 & 770 & - & 140.687 & 6.843 & 111.547 & - & 22.557 \\
\hline Formação Pedag. & 107 & 64 & - & - & 166 & & 673 & - & 89 \\
\hline Bacharelado & 27.326 & 21.285 & 197 & - & 24.207 & 556 & 33.327 & - & 3.833 \\
\hline Tecnólogo & 9.486 & 5.527 & 654 & - & 6.877 & 849 & 5.771 & - & 2.149 \\
\hline Especialização & 79.323 & 55.747 & 10.718 & - & 66.426 & 15.581 & 61.537 & - & 34.203 \\
\hline Aperfeiçoamento & 39.590 & 14.560 & 15.654 & - & 21.176 & 16.859 & 13.754 & - & 23.877 \\
\hline Extensão & 5.041 & 3.571 & 823 & - & 4.938 & 1.688 & 6.039 & - & 2.589 \\
\hline Sequencial & 1.115 & 691 & 206 & - & 751 & 235 & 926 & - & 258 \\
\hline Mestrado Prof. & - & 1.300 & - & - & 2.799 & - & 5.010 & - & 241 \\
\hline Total & 293.842 & 207.035 & 29.022 & - & 268.027 & 42.611 & 238.584 & - & 89.796 \\
\hline
\end{tabular}

Fonte: Brasil (2014, p. 66).

A distribuição geográfica dos cursos e das IES também é assimétrico. Pelos dados de 2014, a região Nordeste possui 41 instituições credenciadas, perfazendo um total $15,59 \%$, assim distribuídos: Bahia, 12; Ceará, 7; Maranhão, 4; Rio Grande do Norte, 3; Piauí, 4; Pernambuco, 5; Alagoas, 2; Sergipe, 2; Paraíba, 2, perfazendo um percentual de $15,59 \%$ do total de IES credenciadas no país, segundo o Instituto de Pesquisas e Administração da Educação (IPAE), conforme Documento Técnico do MEC/CNE (BRASIL, 2014).

No Brasil, a EAD se impõe como necessidade devido à dimensão geográfica do país e ao perfil da população que acorre aos curso de EAD: pessoas já inseridas no mundo do trabalho, nível de renda incompatível com um investimento financeiro vultoso em Educação Superior privada ou impossibilidade de se sustentar em um curso superior público presencial, seja pela incompatibilidade entre horário de estudo e horário de trabalho, seja pela impossibilidade de acessar os campi universitários. Há de se acentuar que a região Nordeste carece de ações de oferta do ensino superior, seja ele presencial ou a distância. Não obstante tudo isto, pode-se hipotetizar que as restrições financeiras do fomento à EAD, bem como a fragilidade da infraestrutura física e tecnológica e a carência de pessoal técnico e docente das IPES sejam responsáveis 
pelo pequeno percentual de oferta, considerando ser a região uma das mais populosas do país. Tudo isto é potencializado pelos graves problemas de infraestrutura de TI nos estados nordestinos, que limitam o alcance de políticas públicas fundadas no uso das TIC.

A Bahia, com doze instituições credenciadas entre universidades públicas e privadas, possui quatro universidades públicas estaduais (UNEB, UEFS, UESB e UESC), e seis ${ }^{5}$ universidades públicas federais (UFBA, UFRB, UFSB, UFOB, UNIVASF $^{6}$ e UNILAB $^{7}$ ). Todas as estaduais estão credenciadas para oferta de cursos EAD. Das instituições federais, apenas a UFOB e a UNILAB ainda não estão credenciadas. Nesse universo, sete IPES são integrantes do Sistema UAB e nenhuma delas faz oferta regular de cursos de graduação na modalidade EAD fora do Sistema UAB.

Assim, é possível afirmar que o ensino superior público no estado da Bahia é dependente do financiamento da UAB para oferta e manutenção da EAD nas respectivas instituições, o que per se é suficiente para testemunhar a falta de uma política estadual para a EAD e a inexistência de uma política acadêmica própria dessas IPES para a EAD, sem falar na ausência de estrutura e de recursos humanos consistentes para implementação da EAD nessas IPES.

No entanto, nem sempre foi assim. As iniciativas no estado da Bahia não começaram pela UAB, e é a partir dessas experiências pré-UAB que as IPES baianas criaram o potencial de recursos humanos e de condições de oferta de cursos a distância de acordo com as exigências da Coordenação de Aperfeiçoamento do Pessoal de Nível Superior (CAPES)/MEC, levando à institucionalização da EAD nas mesmas, com uma política interna de formalização da modalidade.

\subsection{Experiências Pré-UAB na Bahia}

A promulgação da LDB vigente colocou diante dos entes federados um grande desafio: a universalização da formação inicial no nível de graduação para todo o corpo docente da Educação Básica. Ao

5 Dessas seis, duas são pluriestaduais.

6 Pluriestadual - Bahia, Pernambuco e Piauí.

7 Pluriestadual - Bahia e Ceará. tempo em que lançava esse desafio, a LDB também apontava uma estratégia: a EAD.

$\mathrm{O}$ estado da Bahia, em virtude de suas graves assimetrias sociais e de sua grande população, recebeu um desafio considerável. Para ir ao encontro dessa demanda, o estado da Bahia lançou um grande programa de formação de professores, tendo à frente o Centro Estadual de Formação de Professores da Secretaria da Educação, o Instituto Anísio Teixeira (IAT).

Para dar consecução a essa ação, o Estado estruturou a Diretoria de EAD do IAT, criou o Laboratório de EAD do mesmo instituto, montou uma rede de videoconferência com salas em todas as universidades então existentes no estado e nos municípios-sede das Diretorias Regionais de Educação e financiou a qualificação de quadro docente especializado em EAD nas quatro universidades estaduais (UNEB, UEFS, UESC e UESB), mediante a seleção de professores dessas IPES para o Mestrado em Engenharia de Produção na Universidade Federal de Santa Catarina (UFSC).

A experiência de financiamento estadual da educação superior a distância nos idos 2000 teve início com a oferta de Complementação de Licenciatura através da Universidade Federal de Santa Catarina (UFSC), em 2000, e a instalação do Comitê Gestor do programa em 2001, incluindo todas as universidades (públicas e privadas) então existentes na Bahia (UFBA, UNEB, UESC, UEFS, UESC, UCSal e Unifacs). Contudo, esse esforço mostrou-se incapaz de viabilizar um programa robusto e consequente de oferta de ensino superior público a distância, na medida em que o desenho proposto não logrou êxito: apenas a Universidade Salvador (Unifacs), instituição privada, ofertou os cursos a ela destinados no projeto. A Universidade do Estado da Bahia (UNEB), a Universidade Estadual de Santa Cruz (UESC), a Universidade Estadual do Sudoeste da Bahia (UESB), a Universidade Federal da Bahia (UFBA) e a Universidade Católica do Salvador (UCSal) não concretizaram a oferta pactuada.

Assim, essa experiência resultou efetivamente no financiamento de dois cursos de licenciatura (Matemática e Letras com Inglês) em uma instituição privada (Unifacs) e um curso de Complementação de Graduação em uma Instituição Federal 
de outra unidade federativa (UFSC). As razões do fracasso dessa política permanecem como um ponto a ser estudado, na medida em que não existe literatura de lance luz sobre as variáveis que levaram ao malogro do programa estadual de EAD.

Não obstante malogrado, o programa estadual despertou o interesse institucional por EAD das IPES baianas. Embora com ritmo e intensidade diferentes, todas as IPES estaduais começaram a trilhar o caminho de introduzir a EAD como uma variável de sua oferta de Educação Superior.

$\mathrm{O}$ ato seguinte desse processo foi o advento do Programa de Formação Inicial para Professores em Exercício no Ensino Fundamental e no Ensino Médio (Pró-Licenciatura) em âmbito federal. No bojo dessa linha de fomento, a Secretaria da Educação do Estado da Bahia, através do IAT, articulou com a UESC a oferta do curso de Biologia a distância e com a Pontifícia Universidade Católica do Rio de Janeiro a oferta da Licenciatura em História a distância para professores da Rede Estadual de Ensino.

\section{Retratos do Ensino Superior Público a Distância na UNEB}

\subsection{O SISTEMA UAB}

Em 2005, nessa trilha de busca pela expansão da educação a distância no contexto universitário brasileiro, principalmente nas universidades públicas, o Ministério da Educação (MEC) criou o Sistema Universidade Aberta do Brasil (UAB), instituído pelo Decreto $\mathrm{n}^{\circ} 5.800$, de 2006, priorizando a formação de professores da educação básica, através do "desenvolvimento da modalidade de educação a distância, com a finalidade de expandir e interiorizar a oferta de cursos e programas de educação superior no País" (BRASIL, 2006b).

É sempre importante salientar a natureza de estrutura de fomento do Sistema UAB. Embora a sigla UAB possa ser enganosa, a opção brasileira por uma arquitetura de fomento em lugar de uma universidade aberta propriamente dita aponta para a necessidade de lastrear a política sobre a capacidade instalada nas universidades públicas existentes: não obstante pertencerem ao Sistema $\mathrm{UAB}$, os cursos a serem ofertados (professores, projeto pedagógico, material didático) pertencem às universidades ofertantes.
Além de fomentar a modalidade de educação a distância nas instituições públicas de ensino superior, a UAB desenvolve ações no sentido de apoiar pesquisas em metodologias inovadoras de ensino superior respaldadas nas TIC, incentiva a colaboração entre a União e os entes federativos e estimula a criação de centros de formação permanentes por meio dos polos de apoio presencial em localidades estratégicas (COORDENAÇÃO DE APERFEIÇOAMENTO DO PESSOAL DE NÍVEL SUPERIOR, 2015), com a oferta de cursos outros de especialização e de formação continuada, além das graduações.

Para propor e desenvolver tais ações, a proposta da UAB se sustenta em cinco grandes eixos:

a) Expansão pública da educação superior, considerando os processos de democratização e acesso;

b) Aperfeiçoamento dos processos de gestão das instituições de ensino superior, possibilitando sua expansão em consonância com as propostas educacionais dos estados e municípios;

c) Avaliação da educação superior a distância, tendo por base os processo de flexibilização e regulação implantados pelo MEC;

d) Estímulo à investigação em educação superior a distância no país;

e) Financiamento dos processos de implantação, execução e formação de recursos humanos em educação superior a distância (PORTAL UAB, 2012).

Nascido no MEC, no âmbito da extinta Secretaria de Educação a Distância (SEED/MEC), o Sistema UAB é atualmente gerenciado pela Coordenação de Aperfeiçoamento de Pessoal de Nível Superior (CAPES) e tem seu foco na formação de professores, na integração dos sistemas de ensino para a oferta de educação superior a distância com qualidade. Contudo essa qualidade depende e dependerá muito da proposta de educação a distância da instituição de ensino superior (IES) que ofertar e desenvolver os cursos, uma vez que não existe, ainda, estrutura dentro da CAPES/UAB para supervisionar o desenvolvimento dos modelos de EAD implementados com vistas a melhoria, a busca de qualidade como meta. 
Tal conjuntura acentua o fato de que a UAB se restringe a um programa de fomento e, como tal, precisa repousar sobre a expertise das instituições que o acolhem. Se, por um lado, sua condição de programa de fomento garante certa liberdade e dinamicidade ao processo, por outro lado ceifa qualquer tentativa de controle mais estrito da proposta pedagógica de um curso dado: no modelo brasileiro vigente, haverá tantas abordagens de EAD no Ensino Superior Público quantas forem as universidades a ofertar cursos financiados pela UAB.

Os cursos ofertados pelas diversas IES credenciadas através do Sistema UAB são de Licenciaturas, de Bacharelados, de Tecnólogo e de Especializações, na sua grande maioria voltados para professores da rede pública de Educação Básica, principalmente, e para o público em geral que esteja interessado em um dos cursos na modalidade a distância. Vale salientar que as seleções são feitas a partir de editais e o quantitativo de vagas destinadas ao atendimento da demanda social é definido por cada IES de acordo com as necessidades dos governos locais.

Além dos cursos regulares de graduação e pós-graduação aprovados em cada IES, o Sistema UAB também oferta e gerencia as pós-graduações lato sensu do Programa Mídias na Educação, especializações destinadas aos docentes como preparo para trabalhar com os temas transversais dos currículos da educação básica; cursos ofertados em nível de graduação, bacharelado e pós-graduação lato sensu do Programa Nacional de Formação em Administração Pública (PNAP) (COORDENAÇÃO DE APERFEIÇOAMENTO DO PESSOAL DE NÍVEL SUPERIOR, 2015).

Nesse contexto, a UNEB desenvolve hoje, através da $\mathrm{UAB}$, diversas ações no âmbito da EAD que contribuíram para que, ao longo dos primeiros quinze anos do século XXI, fosse possível existir uma esfera que cuide especificamente da educação a distância em todas as suas dimensões, institucionalmente, na UNEB, principalmente no que tange ao desenvolvimento de ações de ensino, pesquisa e extensão.

Das ações desenvolvidas pela UNEB no âmbito da UAB, podemos destacar a oferta regular de 17 cursos que atendem a todo o território baiano, distribuídos em 33 polos de apoio presencial do Sistema UAB. Atualmente estão ativos onze cursos de graduação, atendendo a um total de 3.568 estudantes ativos, distribuídos em 134 turmas, como podemos ver na Tabela 4.

Tabela 4 - Oferta de cursos ativos na modalidade EAD/UAB UNEB em 2015

\begin{tabular}{c|l|c|c|c}
\hline $\mathbf{N}^{\circ}$ & \multicolumn{1}{|c|}{ Cursos UNEB } & Polos & Turmas & Alunos ativos \\
\hline 1 & BIOLOGIA & 05 & 07 & 158 \\
\hline 2 & CIÊNCIAS DA COMPUTAÇÃO & 06 & 08 & 219 \\
\hline 3 & EDUCAÇÃO FÍSICA & 06 & 09 & 222 \\
\hline 4 & GEOGRAFIA & 11 & 16 & 417 \\
\hline 5 & HISTÓRIA & 11 & 13 & 407 \\
\hline 6 & LETRAS ESPANHOL & 12 & 14 & 264 \\
\hline 7 & LETRAS INGLÊS & 09 & 10 & 235 \\
\hline 8 & LETRAS PORTUGUÊS & 07 & 10 & 287 \\
\hline 9 & MATEMÁTICA & 16 & 19 & 507 \\
\hline 10 & PEDAGOGIA & 13 & 21 & 727 \\
\hline 11 & QUÍMICA & 05 & 07 & 125 \\
\hline & TOTAL & & 134 & 3568 \\
\hline
\end{tabular}

Fonte: Coordenação de Aperfeiçoamento do Pessoal de Nível Superior (2015). 
No que tange à oferta de extensão no Sistema UAB, atualmente a UNEB tem seis cursos ativos, todos da SECAD, no entanto não há nenhum iniciado com estudantes matriculados. Fora do Sistema UAB, a UNEB oferta dois grandes cursos de extensão a distância: o Curso de Aperfeiçoamento em Tecnologias Educacionais (CATE), financiado pela Secretaria da Educação do Estado da Bahia para 31.163 professores da Rede Estadual, e o Projeto Telecentros, financiado pelo Ministério das Comunicações, que objetivou dar formação a gestores e monitores do telecentros e, posteriormente, foi aberto para formação em TIC para jovens do Ensino Médio, ofertando 4.200 vagas para todo o território nacional.

No caso dos cursos de pós-graduação lato sen$s u$, são ofertados cursos no âmbito dos projetos da SECAD, PNAP e da própria UNEB, perfazendo um total atual de oito cursos ativos, cinco com oferta e três à espera da composição das turmas, como se pode verificar na Tabela 5 .

Tabela 5 - Oferta de cursos de especialização EAD/UNEB - 2015

\begin{tabular}{|c|c|c|c|c|c|}
\hline $\mathbf{N}^{\circ}$ & Cursos UNEB & Turmas & Polos & Alunos & Form. prof. \\
\hline 1 & EDUCACAO A DISTÂNCIA & 04 & 04 & 105 & UAB \\
\hline 2 & $\begin{array}{l}\text { EDUCAÇÃO EM DIREITOS } \\
\text { HUMANOS }\end{array}$ & 00 & 00 & 00 & SECAD \\
\hline 3 & $\begin{array}{l}\text { EDUCACAO PARA A } \\
\text { DIVERSIDADE }\end{array}$ & 00 & 00 & 00 & SECAD \\
\hline 4 & $\begin{array}{l}\text { GÊNERO E DIVERSIDADE NA } \\
\text { ESCOLA }\end{array}$ & 00 & 00 & 00 & SECAD \\
\hline 5 & GESTÃO EM SAÚDE & 04 & 04 & 119 & PNAP \\
\hline 6 & GESTÃO PÚBLICA & & & 147 & PNAP \\
\hline 7 & GESTÃO PÚBLICA MUNICIPAL & 05 & 05 & 175 & PNAP \\
\hline \multirow[t]{2}{*}{8} & $\begin{array}{l}\text { INTERDISCIPLINAR EM } \\
\text { ESTUDOS SOCIAIS E } \\
\text { HUMANIDADES }\end{array}$ & 07 & 07 & 197 & UAB \\
\hline & TOTAL & 20 & 20 & 743 & \\
\hline
\end{tabular}

Fonte: Coordenação de Aperfeiçoamento do Pessoal de Nível Superior (2015).

Assim, a EAD da UNEB hoje está sustentada essencialmente pela existência dos recursos do Sistema UAB, uma vez que todos os cursos de graduação e pós-graduação que estão em oferta com alunos matriculados são feitos a partir do que dispõe a UAB na UNEB (recursos humanos, financeiros, estruturais). Mesmo assim, os cursos de graduação são ofertados regularmente no processo seletivo de vestibular, com entrada regular e calendário específico da universidade para seu desenvolvimento.

Podemos constatar que os cursos a distância financiados pelo Sistema UAB hoje representam a realidade da educação a distância na UNEB, desde o modelo de curso, estrutura organizacional de gestão até as condições de financiamento da modalidade, atendendo atualmente um total de 4.311 pessoas com a oferta de educação na modalidade a distância.

\subsection{EAD NOS CURSOS PRESENCIAIS DE GRADUAÇÃO}

A prática pedagógica mediada pelas TIC, principalmente no ensino superior, prevê a condição de que o professor e os estudantes possam 
reelaborar o que thes é apresentado como dado, possibilitando que saiam da condição de meros reprodutores, uma vez que inclui capacidades de elaborações novas, a partir das quais permite reconhecer e conhecer os contornos ainda nublados do processo de construção do conhecimento, isto é, "possibilita a potencial percepção dos diversos fenômenos da vida social e estabelece relações tendo como referência o próprio processo formativo e a sociedade como um todo" (SALES; NONATO, 2014). Em certa medida, a inserção da EAD pode funcionar com um instrumento de mobilização do potencial de autonomia dos sujeitos, na medida em que impõe a manifestação do potencial criativo e autônomo dos sujeitos, sob pena de inviabilizar as trocas pedagógicas que constituem o processo de educação mediada.

Nessa perspectiva, uma das marcas mais acentuadas da contemporaneidade é o lugar que as TIC ocupam

[...] na organização da sociedade, na vida pessoal de cada cidadão, principalmente, nas ações e atos educacionais. Embora se possa arguir que a tecnologia é um desdobramento natural da condição humana e tem sido uma marca ao longo da história, pois o último quadrante do século passado e os primeiros anos deste século têm testemunhado um desenvolvimento tecnológico sem precedentes, acompanhado por uma imbricação homem-máquina que tem alcançado quase todas as dimensões da vida humana, inclusive a intelectual e afetiva. (SALES, 2013, p. 87).

Por isso, a prática da educação a distância mediada pelo uso das TIC, especificamente com o uso do ambiente virtual de aprendizagem (AVA), contribui dinamicamente para a disponibilização de recursos que possibilitam a comunicação, consolidação de redes, as práticas de colaboração e da autonomia dos sujeitos aprendizes no desenvolvimento do processo de ensino-aprendizagem. Esse foi um dos motivos de iniciar o processo de adesão à oferta de componentes curriculares a distância até o limite de $20 \%$ da carga horária total do curso nos cursos presenciais da UNEB, conforme a norma federal vigente.

Diante de tal possibilidade, a UNEB, através da Resolução CONSEPE/UNEB n ${ }^{\circ}$ 1.508/2012, con- sentiu que os cursos dos diversos campi aderissem a esse tipo de oferta e ampliassem a possibilidade de desenvolvimento da formação no âmbito do ensino superior, em consonância com a normatização federal atinente (UNIVERSIDADE DO ESTADO DA BAHIA, 2012).

Para participar da oferta dos $20 \%$ semipresenciais, o curso deve ser reconhecido pelo órgão competente do Sistema de Ensino ao qual pertence, integrar as TIC às práticas de educativas para os processos de ensino e de aprendizagem, apresentar um projeto de trabalho para implementação do componente curricular proponente no qual devem constar as metodologias de desenvolvimento, recursos a serem utilizados, desenho pedagógico, apresentação e delimitação dos conteúdos a serem trabalhados e os instrumentos de avaliação a serem utilizados, além, é claro, de um cronograma de curso.

No caso da UNEB, a adesão faz-se semestralmente e "os componentes curriculares devem ser devidamente cadastrados no sistema de acompanhamento pedagógico da UNEB com o indicativo da oferta EAD" (SALES; NONATO, 2014), sendo que os professores devem atender ao perfil recomendado na Resolução com formação e/ou experiência no trabalho pedagógico com as TIC ou EAD, visto que este desenvolverá mais de $50 \%$ do trabalho pedagógico através do Ambiente Virtual de Aprendizagem (AVA) Moodle.

Nesse caso específico do desenvolvimento da EAD nos cursos presenciais da UNEB, o professor

[...] terá múltiplas funções, assumindo o papel de formador, design de curso e pesquisador. Dessa forma, ele será o responsável por planejar e construir o desenho didático dos cursos de cada componente curricular, disponibilizar materiais e recursos que vão permitir que a aprendizagem aconteça, além de fazer a mediação didática e proceder a avaliação, além dos momentos presenciais, nas ações pedagógicas que são desenvolvidas no AVA Moodle. (SALES; NONATO, 2014).

Nesse contexto, entre 2010 e 2014 já foram ofertadas 176 disciplinas dentro do projeto de oferta semipresencial, $20 \%$ a distância, atendendo a um total de 4.407 discentes, como podemos verificar nos Gráficos 2 e 3. 
Gráfico 2 - Quantitativo de disciplinas ofertadas e departamentos atendidos $-2010-2014$

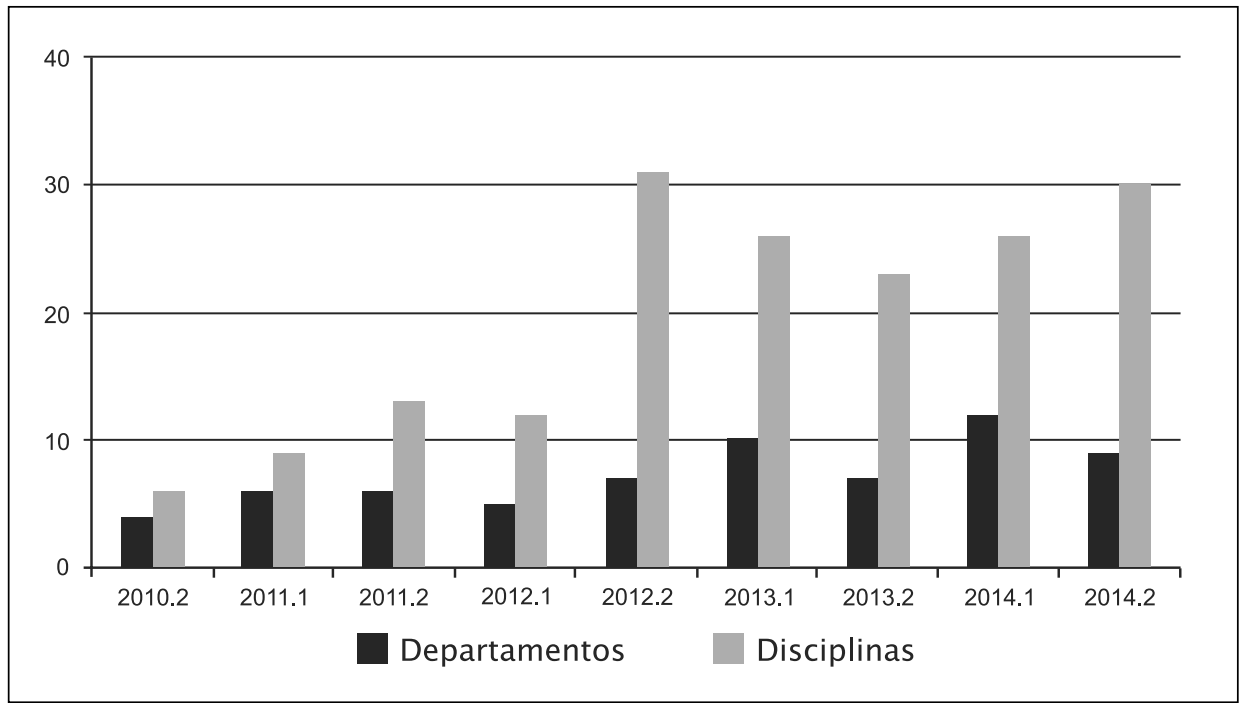

Fonte: Universidade do Estado da Bahia (2015).

Gráfico 3 - Quantitativo de estudantes atendidos nas disciplinas ofertadas EAD nos cursos presenciais por semestre - 2010 a 2014

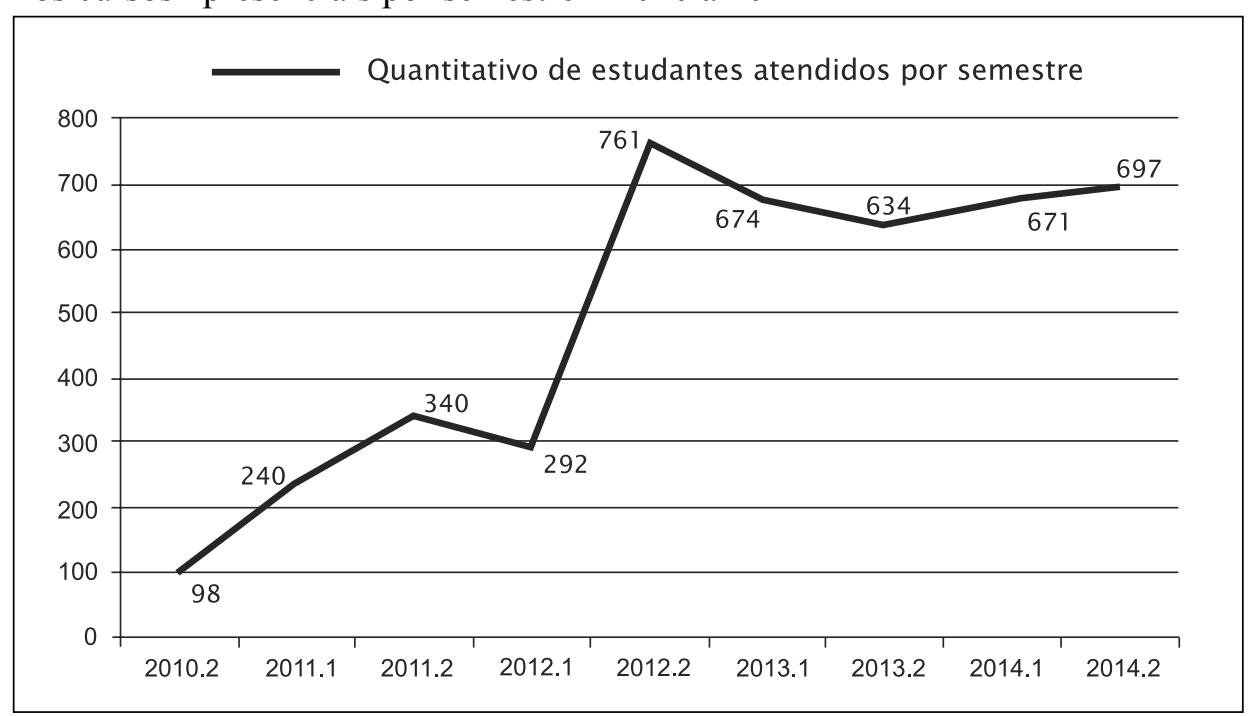

Fonte: Universidade do Estado da Bahia (2015).

Pode-se perceber nos Gráficos 2 e 3 que, em 2012, a adesão à oferta de disciplinas na modalidade a distância cresceu. Isto se deu pelo trabalho de institucionalização realizado pela Gerência de Educação a Distância (GEAD) da Pró-Reitoria de Ensino de Graduação (PROGRAD) da UNEB,${ }^{8}$ que

8 Órgão já extinto e substituído pela Unidade Acadêmica de Educação a Distância (UNEAD), conforme Resolução CONSU/UNEB n. 1.051/2014 (UNEB, 2014). a partir de reuniões de esclarecimento, formação continuada de professores e diálogo permanente com os Colegiados de Curso, apresentou a proposta e trabalhou para implementar as ofertas. Após esse período, verifica-se que a oferta manteve-se estável. Este fato pode ser relacionado ainda à falta de confiança e conhecimento existente no que diz respeito à modalidade, principalmente por parte dos professores. 
Em relação às ofertas feitas, duas características são marcantes: a) o fato da maioria dos professores que são responsáveis pelas propostas encaminhadas para o projeto dos $20 \%$ já possuir alguma experiência com o uso das TIC como recurso pedagógico, como parte de suas atividades cotidianas ou tem alguma experiência com EAD (tutoria, docência, estudante) ou, ainda, tem formação na área de tecnologias e educação ou em EAD. Esta característica promove, em muitos casos, uma maior interação do docente com a proposta apresentada pela UNEAD; b) o fato da maioria da oferta ser aderida por campi do interior do estado, como podemos confirmar no Gráfico 4 a seguir.

Gráfico 4 - Relação adesão a oferta de disciplinas EAD nos cursos presenciais capital/interior - 2010-2014

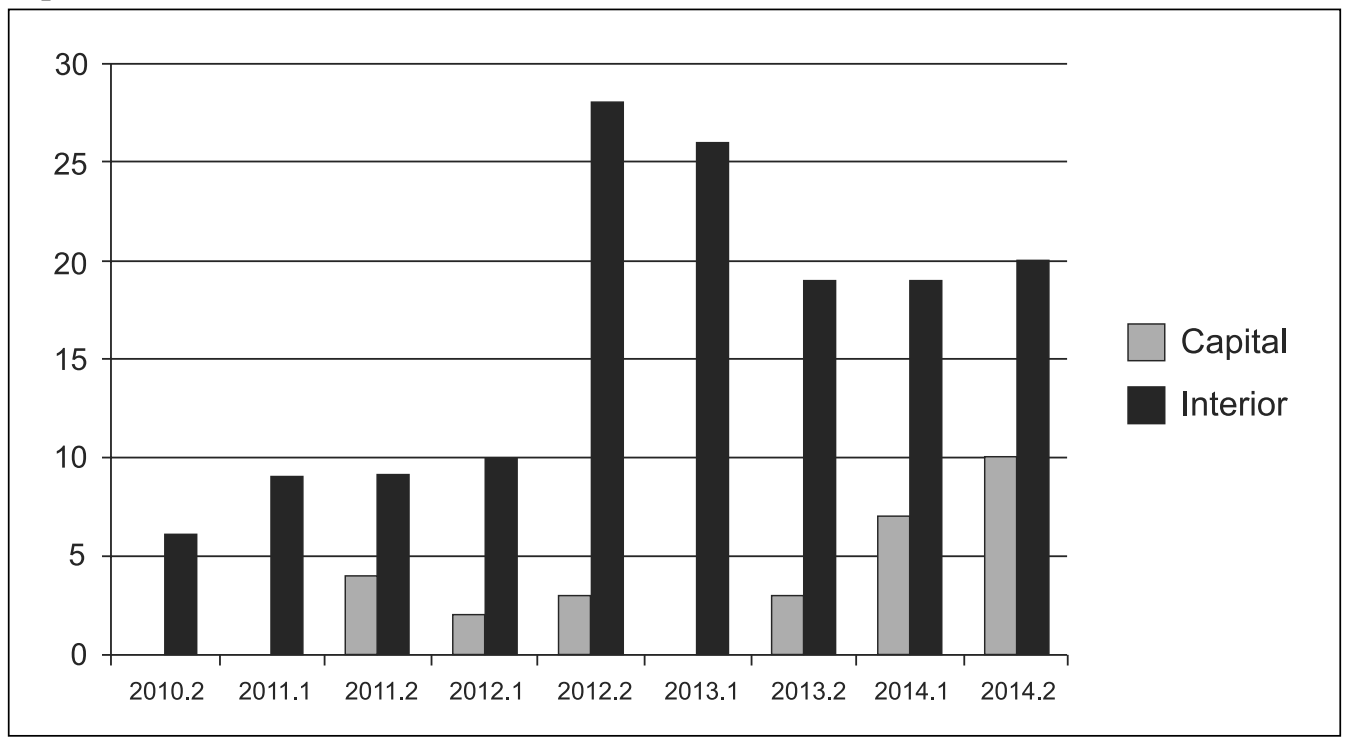

Fonte: Universidade do Estado da Bahia (2015).

Entre 2010 e 2014, da oferta de 176 disciplinas, apenas 29 são de oferta por Departamentos do Campus I (Salvador), perfazendo apenas um total de $16,47 \%$ da oferta geral, confirmando a interiorização da EAD, como pode ser claramente visto no Gráfico 4 exposto. Desse modo, é de se notar que a política de adesão a oferta de disciplinas na modalidade a distância na UNEB também está voltada ao encurtamento dos deslocamentos que são realizados por estudantes e, principalmente, professores para os campi do interior do Estado.

Esse retrato nos apresenta mais uma característica da oferta dos componentes curriculares no projeto dos $20 \%$ a distância que é a interiorização da $\mathrm{EaD}$, que se dá

[...] pela flexibilização dos horários de atendimento dos professores nos campi do interior e pelo fato de implicar diretamente na redução do número de deslocamentos destes para ministrarem suas aulas, mesmo que dentro da proposta do projeto o professor precisa dar atendimento aos estudantes conforme encaminhar Regimento Interno da Universidade. (SALES; NONATO, 2014).

Nesse contexto, a oferta de componentes curriculares a distância nos cursos presenciais da Universidade continua crescendo e contribuindo muito para a qualificação dos processos formativos em EAD no que diz respeito ao corpo docente, com a formação em serviço, e ao corpo discente, com a formação em processo, ampliando desta forma uma cultura institucional em relação à utilização das TIC como recursos de comunicação, produção e difusão do conhecimento, além de possibilitar a consolidação do espaço da EAD nas propostas de formação de licenciaturas e bacharelados no ensino superior do nosso estado dentro de uma Universidade Pública multicampi.

No entanto, esse processo apresenta fragilidades e muitos avanços no que se refere à institucionalização da EAD na UNEB. A inserção de componentes 
a distância nos cursos presenciais de graduação precisa tornar-se orgânica e sistêmica, atendendo às necessidades tanto operacionais quanto pedagógicas dos cursos, mas essencialmente integrando a EAD ao processo formativo dos alunos, naturalizando a EAD como uma modalidade de ensino disponível aos educandos.

A inserção de componentes a distância atua como dinamizador do fluxo de integralização curricular da graduação, oportunizando novas experiências/vivências acadêmicas. Nos cursos de licenciatura, essa oferta cumpre ainda o papel de permitir que os discentes experimentem a EAD, modalidade de educação na qual o futuro profissional poderá vir a atuar. A perspectiva da inclusão de componentes curriculares a distância nos cursos presenciais é o pavimentar do caminho para o blended learning. A isto só se chegará se a oferta deixar de ser acidental e pontual e passar a ser orgânica (estruturada a partir da natureza mesma dos componentes curriculares a serem estudados, dependente das habilidades cognitivas que se pretende desenvolver e da modalidade que melhor se adapta a tais objetivos), sistêmica (inserida de modo estável e sistemático na proposta curricular) e livre (condicionada às necessidades dos estudantes para lhes proporcionar um fluxo livre e dinâmico de formação que melhor se adapte às contingências da vida e aos condicionamentos do mundo contemporâneo).

\section{Conclusões}

A construção de uma universidade pública plural e consciente de seu papel como agente de promoção do desenvolvimento humano passa por sua atuação em todos os níveis e através de todos os mecanismos que estão a sua disposição. Nestes dias, considerando o lugar que as TIC ocupam no cenário socioeconômico, esse processo passa necessariamente pela apropriação das TIC no processo ensino-aprendizagem e pela EAD. Nesse sentido, a história da oferta de EAD nas universidades públicas ajuda a discernir o ritmo com o qual as IPES estão assumindo seu papel no cenário social que se configura a partir da emergência das TIC.

Como este estudo buscou demonstrar, a história da oferta pública de ensino superior a distância na Bahia está marcada pelo advento do Sistema UAB: ele é um divisor de águas. Não obstante o reconhecimento da importância das experiências de ofertas de cursos a distância anteriores ao advento da UAB nas universidades públicas baianas, embora limitadas, o financiamento da UAB instituiu um ambiente concreto para a criação de cursos a distância nas IPES baianas e consequente crescimento do número de vagas ofertadas a distância e número total de vagas públicas no ensino superior. Neste campo, os avanços na UNEB são incontestáveis: aumento do número de vagas, aumento do número de cursos, criação de um órgão universitário para gestão de EAD (UNEAD/UNEB), introdução de componentes ofertados na modalidade a distância nos cursos presenciais de graduação e atuação consistente na graduação, pós-graduação e extensão na modalidade a distância.

Não obstante a criação de um órgão universitário para gestão de EAD (UNEAD/UNEB) e a introdução de componentes ofertados na modalidade a distância nos cursos presenciais de graduação não sejam diretamente vinculados aos recursos da $\mathrm{UAB}$, dificilmente esses avanços teriam sido concretizados sem que a demanda nascida da política de fomento do Sistema UAB tivesse crescido a ponto de criar as condições políticas para justificá-los.

Nesse ponto, há de se recordar que a oferta de componentes curriculares na modalidade a distância nos cursos presenciais de graduação se insere em uma cultura institucional na qual a EAD está se consolidando, vale-se de um aparato tecnológico e de gestão que dá suporte às demandas da UAB na UNEB e utiliza os docentes da instituição que se aproximaram da EAD ou obtiveram experiência docente nesta modalidade no contexto dos cursos de graduação a distância financiados pela UAB.

Também a estrutura de gestão - UNEAD/UNEB - é tributária da necessidade de gestão administrativa e acadêmica gerada pelos cursos de graduação e pós-graduação a distância financiados pela CAPES no Sistema UAB. Todavia, sua atuação ultrapassa os limites do Sistema UAB na UNEB e o contém (a Coordenação UAB local é uma área da UNEAD), tornando-se um fator impulsionador do crescimento institucional da EAD na UNEB.

Não obstante tudo isso, a EAD nas IPES baianas, notadamente na UNEB, ainda está longe de ser 
considerada como elemento plenamente integrado à vida acadêmica dessas instituições universitárias. A centralidade das licenciaturas no quadro de ofertas de cursos na modalidade a distância atua como um fator restritivo do processo de integração da EAD à vida acadêmica ordinária das IPES. Sem um leque de bacharelados a ofertar, a EAD nas IPES limita-se à função instrumental de mecanismo das políticas públicas de formação de professores para a Educação Básica e, como tal, não consegue disseminar-se por todas as áreas do conhecimento nas quais as IPES atuam.

Grande parte desse problema pode ser explicado também pela natureza especial dos cursos ofertados e pelo financiamento específico que recebem, na medida em que o modelo de financiamento implementado pela UAB segrega os cursos a distância em uma categoria distinta dos demais cursos das IPES, desestimulando a naturalização desses cursos como componentes ordinários do portfólio de cursos dessas instituições.

$O$ crescimento que a EAD tem experimentado nas IPES em virtude do Sistema UAB traz em si outro problema de origem: o financiamento da UAB não está direcionado à construção de estruturas permanentes de EAD nas IPES, mas visa a oferta de cursos e vagas. Essa forte contradição, por um lado, fragiliza a própria política de oferta de cursos e vagas na modalidade a distância nas IPES, na medida em que não favorece o desenvolvimento de estruturas sólidas de EAD nas IPES e de inserção da EAD na cultura organizacional dessas universidades, enraizando a EAD nessas instituições.

Por tudo isso, a marca da transitoriedade continua a sombrear o futuro da EAD nas IPES baianas. Se, por um lado, o surgimento de cursos na modalidade a distância nas IPES é um forte impulsionador do esforço pela institucionalização da EAD nessas universidades, isso não passa de um efeito colateral, na medida em que a política federal de financiamento não contempla ações de longo prazo e investimentos sólidos em infraestrutura e institucionalização, conservando a transitoriedade de um financiamento com limites temporais claramente definidos como um perigo constante de desmantelamento do frágil edifício em que se conforma a EAD nas IPES baianas.

Não obstante tudo isso, a EAD continua a ser uma aposta para ao futuro da Educação Superior Pública. As experiências até aqui gestadas apontam para a necessidade de pensar a difusão do conhecimento por canais mais flexíveis e dinâmicos, moldando-se com maior facilidade à dinâmica da vida do século XXI, experiência na qual a EAD tem dado frutos bastante significativos.

\section{REFERÊNCIAS}

ASSOCIAÇÃO BRASILEIRA DE EDUCAÇÃO A DISTÂNCIA (ABED). Censo EaD.br. Relatório analítico da aprendizagem a distância no Brasil 2013/Censo EaD.br: analytic report of distance learning in Brazil. Tradução Maria Thereza Moss de Abreu. Edição bilíngue: português/inglês. Curitiba: Ibpex, 2014.

ALVES, João Roberto M. A educação superior a distância: uma análise de sua evolução no cenário brasileiro. 2005. Disponível em: <http://www.abed.org.br/site/pt/midiateca/noticias_ead/20/2005>. Acesso em: 08 maio 2015.

ARETIO, Lorenzo Garcia. Educación a distancia hoy. Madrid: UNED, 1987.

BELLONI, Maria Luiza. Educação a Distância. 4. ed. Campinas: Autores Associados, 2006.

BRASIL. Presidência da República. Lei n. 9.394, de 20 de dezembro de 1996. Estabelece as diretrizes e bases da educação. Brasília, DF, 1996. Disponível em: <http://www.planalto.gov.br/ccivil_03/leis/19394.htm>. Acesso em: 01 jun. 2015.

. Ministério da Educação. Decreto no 2.494, de 10 de fevereiro de 1998. Regulamenta o Art. 80 da LDB (Lei n. ${ }^{\circ}$ 9.394/96). Brasília, DF, 1998a. Disponível em: <http://portal.mec.gov.br/seed/arquivos/pdf/tvescola/leis/ D2494.pdf>. Acesso em: 01 jun. 2015.

Ministério da Educação. Decreto $\mathbf{n}^{\mathbf{0}}$ 2.561, de 27 de abril de 1998. Altera a redação dos art. 11 e 12 do $\overline{\text { Decreto }}$ n. ${ }^{\circ}$ 2.494, de 10 de fevereiro de 1998, que regulamenta o disposto no art. 80 da Lei n. ${ }^{\circ}$ 9.394, de 20 de 
dezembro de 1996. Brasília, DF, 1998b. Disponível em: <http://portal.mec.gov.br/seed/arquivos/pdf/tvescola/leis/ D2561.pdf>. Acesso em: 01 jun. 2015.

. Ministério da Educação. Portaria Ministerial no 301, de 7 de abril de 1998. Brasília, DF, 1998c. Disponível em: $<$ http://portal.mec.gov.br/seed/arquivos/pdf/tvescola/leis/port301.pdf $>$. Acesso em: 01 jun. 2015.

Conselho Nacional de Educação. Resolução n ${ }^{\circ}$ 1, de 3 de abril de 2001. Estabelece normas para o funcionamento de curso de pós-graduação. Brasília, DF, 2001a. Disponível em: <http://portal.mec.gov.br/seed/arquivos/ pdf/tvescola/leis/CES0101.pdf $>$. Acesso em: 01 jun. 2015.

Ministério da Educação. Portaria Ministerial n 2.253, de 18 de outubro de 2001. Brasília, DF, 2001b. Disponível em: <http://www.cmconsultoria.com.br/legislacao/portarias/2001/por_2001_2253_MEC_regulamentacao_oferecimento.pdf>. Acesso em: 01 jun. 2015.

Ministério da Educação. Portaria Ministerial n 335, de 6 de fevereiro de 2002. Brasília, DF, 2002. Disponível em: <http://portal.mec.gov.br/sesu/arquivos/pdf/P335.pdf >. Acesso em: 01 jun. 2015.

Presidência da República. Decreto no 5.622, de 19 de dezembro de 2005. Regulamenta o art. 80 da Lei $\overline{n^{\circ}}$ 9.394, de 20 de dezembro de 1996 (LDB). Brasília, DF, 2005. Disponível em: <http://www.planalto.gov.br/ ccivil_03/_Ato2004-2006/2005/Decreto/D5622.htm>. Acesso em: 01 jun. 2015.

Presidência da República. Decreto n ${ }^{\circ} \mathbf{5 . 7 7 3}$, de 9 de maio de 2006. Dispõe sobre o exercício das funções de regulação, supervisão e avaliação de instituições de educação superior e cursos superiores de graduação e sequenciais no sistema federal de ensino. Brasília, DF, 2006a. Disponível em: <http://www.planalto.gov.br/ ccivil_03/_Ato2004-2006/2006/Decreto/D5773.htm>. Acesso em: 01 jun. 2015.

Presidência da República. Decreto n $^{\circ}$ 5.800, de 8 de junho de 2006. Dispõe sobre o Sistema Universidade Aberta do Brasil - UAB. Brasília, DF, 2006b. Disponível em: <http://www.planalto.gov.br/ccivil_03/_ato20042006/2006/decreto/d5800.htm>. Acesso em: 01 jun. 2015.

Presidência da República. Decreto $\mathbf{n}^{\circ} \mathbf{6 . 3 0 3}$, de 12 de dezembro de 2007. Altera dispositivos dos Decretos nos 5.622, de 19 de dezembro de 2005, e 5.773, de 9 de maio de 2006. Brasília, DF, 2007a. Disponível em: <http:// www.planalto.gov.br/ccivil_03/_Ato2007-2010/2007/Decreto/D6303.htm>. Acesso em: 01 jun. 2015.

Ministério da Educação. Portaria Ministerial no 01, de 10 de janeiro de 2007. Brasília, DF, $2007 b$. Disponível em: <http://portal.mec.gov.br/seed/arquivos/pdf/legislacao/portaria1.pdf>. Acesso em: 01 jun. 2015.

Ministério da Educação. Portaria Ministerial no 02, de 10 de janeiro de 2007. Brasília, DF, 2007c. Disponível em: <http://portal.mec.gov.br/seed/arquivos/pdf/legislacao/portaria2.pdf $>$. Acesso em: 01 jun. 2015.

Ministério da Educação. Portaria Ministerial no 10, de 02 de julho de 2009. Brasília, DF, 2007d. Disponível em: $<$ http://portal.mec.gov.br/dmdocuments/portaria10_seed.pdf > . Acesso em: 01 jun. 2015.

Ministério da Educação. Portaria Ministerial no 40, de 13 de dezembro de 2007. Brasília, DF, 2007e. Disponível em: <http://portal.mec.gov.br/seed/arquivos/pdf/ead/port_40.pdf>. Acesso em: 01 jun. 2015.

Ministério da Educação. Conselho Nacional de Educação. Produto 1 - Documento Técnico. Consultora: LIMA, Daniela da C. B. Pereira. Brasília, DF, 2014. Disponível em: <http://portal.mec.gov.br/index. php?option $=$ com_docman\&view $=$ download\&alias $=16510$-produto-01-estudo-analitico\&Itemid $=30192>$. Acesso em: 12 maio $201 \overline{5}$.

CASTELLS, Manuel. A sociedade em rede. 8. ed. Trad. Roneide Venancio Majer. São Paulo: Paz e Terra, 2003. v. 1.

CELLARD, A. A análise documental. In: POUPART, J. et al. A pesquisa qualitativa: enfoques epistemológicos e metodológicos. Petrópolis, RJ: Vozes, 2008. p. 295-316.

COORDENAÇÃO DE APERFEIÇOAMENTO DO PESSOAL DE NÍVEL SUPERIOR (CAPES). Universidade Aberta do Brasil. Cursos ofertados. Disponível em: $<$ http://uab.capes.gov.br/index.php?option=com_content\&vi ew $=$ article $\& i d=12 \& I t e m i d=25>$. Acesso em: 02 maio 2015 .

FILATRO, Andréa. Design instrucional contextualizado. São Paulo: Senac, 2004.

Design instrucional na prática. São Paulo: Pearson, 2008.

HOLMBERG, B. Theory and practice of distance education. London: Routledge, 1989. 
INSTITUTO NACIONAL DE ESTUDOS E PESQUISA EM EDUCAÇÃO ANÍSIO TEIXEIRA (INEP). Instrumento de avaliação de cursos de graduação presencial e a distância. Brasília, DF, 2012. Disponível em: $<$ http:// download.inep.gov.br/educacao_superior/avaliacao_cursos_graduacao/instrumentos/20 12/instrumento_com_alteracoes_maio_12.pdf $>$. Acesso em: 01 jun. 2015.

KEEGAN, D. Theoretical principles of distance education. London: Routledge, 1993.

LITTO, Frederic Michael; FORMIGA, Manuel Marcos Maciel (Org.). Educação a distância: o estado da arte. São Paulo: Pearson Education do Brasl, 2009.

LUDKE, Menga; ANDRË, Marli E. D. A. Pesquisa em educação. São Paulo: EPU, 1986.

NUNES, Ivônio Barros. A história da EAD no mundo. In: LITTO, Frederic Michael; FORMIGA, Manuel Marcos Maciel (Org.). Educação a distância: o estado da arte. São Paulo: Pearson Education do Brasl, 2009. p. 2-8.

PETERS, Otto. Didática do ensino a distância. São Leopoldo, RS: Unisinos, 2003.

A educação a distância em transição. São Leopoldo, RS: Editora UNISINOS, 2004.

SÁ-SILVA, J. R; ALMEIDA, C. D; GUINDANI, J. F. Pesquisa documental: pistas teóricas e metodológicas. Revista Brasileira de História e Ciências Sociais, Ano I, v. 1, n. 1, p. 1-15, 2009.

SALES, Mary V. S. Proformação: ressignificando o uso da mídia impressa na educação a distância para formação de professores. 2006. 205f. Dissertação (Mestrado em Educação) - Programa de Pós-Graduação em Educação e Contemporaneidade, Universidade do Estado da Bahia (UNEB), Salvador, 2006.

Tessituras entre mediação e autoria nas práticas de currículo na formação a distância: a construção do conhecimento no contexto universitário. 2013. 281f. Tese (Doutorado em Educação) - Programa de Pós-Graduação em Educação, Universidade Federal da Bahia (UFBA), Salvador, 2013.

SALES, Mary V. S.; NONATO, Emanuel do R. S. Educação a distância em cursos presenciais de graduação: o estudo de uma experiência ação. In: ENCONTRO DE PESQUISA EDUCACIONAL DO NORTE-NORDESTE, 22., 2014, Natal. Anais... Natal: Universidade Federal do Rio Grande do Norte/Centro de Educação/Programa de Pós-graduação em Educação, 2014.

UNIVERSIDADE DO ESTADO DA BAHIA (UNEB). Conselho Superior de Ensino, Pesquisa e Extensão. Resolução $\mathrm{n}^{\circ}$ 1.508, de 20 de agosto de 2012. Diário Oficial do Estado da Bahia, Poder Executivo, Salvador, BA, 21 ago. 2012, p. 19-20.

Conselho Universitário. Resolução n ${ }^{\circ} 1.051$, de 15 de maio de 2014. Diário Oficial do Estado da Bahia, Poder Executivo, Salvador, BA, 29 maio 2014, p. 23.

. Unidade Acadêmica de Educação a Distância. Coordenação do Projeto da Oferta Semipresencial. Slides

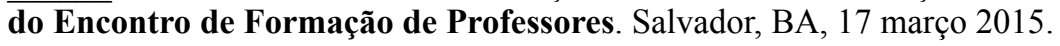

Recebido em: 30.06 .2015

Aprovado em: 15.10 .2015 